\title{
O processo de escolha das fontes de texto: uma exploração sobre a associação entre padrões tipográficos, tipos e sabores.
}

\author{
The process of text typefaces choice: an exploration of the association between \\ typographic patterns, types and tastes.
}

Luiza Falcão, Luis Felipe Cavalcanti

tipografia, escolha, fontes de texto, sabores

\begin{abstract}
Este trabalho visa explorar a assimilação das diferenças formais entre as fontes de texto no momento da escolha tipográfica. Apoiado na premissa da designer de tipos Zuzana Licko (1997) de que as letras, quando aplicadas no contexto de texturas mostram de maneira mais explícita suas características estilísticas e conceituais, o presente estudo visa comparar a compreensão de tais características na utilização em manchas textuais e em padrões tipográficos. Inspirado nas pesquisas do laboratório Type Tasting (2016), o estudo foi realizado com trinta sujeitos e estruturado para simular o processo de montagem de embalagens para líquidos representantes dos cinco sabores primários: o doce, o azedo, o salgado, o amargo e o neutro.
\end{abstract}

typeface, choice, text fonts, tastes

This paper aims to explore the assimilation of formal differences between text sources at the time of typographic choice. Based on the premise of type designer Zuzana Licko (1997) that the letters, when applied in the context of textures show more explicitly their stylistic and conceptual characteristics, the present study aims at comparing the comprehension of such characteristics in the use in texts and in typographic patterns. Inspired by the researches of the Type Tasting laboratory (2016), the study was carried out with thirty subjects and structured to simulate the process of assembling the packaging of liquids representing the five primary tastes: sweet, sour, salty, bitter and neutral.

\section{Introdução}

Ao iniciar o projeto de um artefato gráfico cujo conteúdo é composto majoritariamente por textos verbais, o designer gráfico se encontra diante da necessidade de escolher a fonte que atuará como a interface entre o leitor e a informação escrita. Há algumas décadas estamos vivenciando um ambiente produtivo favorável para o desenho de fontes tipográficas. $A$ utilização dos computadores pessoais característica do século XXI oferece fácil acesso a informações que facilitam o estudo e a prática do desenho de tipos, além de uma flexibilidade técnica que permite inovações e sutilezas formais não tão fáceis de serem alcançadas até então. O fato reflete no aumento da biblioteca de tipografias disponível para uso: o site MyFonts, um dos maiores portais de distribuição de fontes do mundo, contabiliza atualmente mais de 14.000 famílias tipográficas. É dentro desse universo de opções que reside o desafio da escolha da fonte mais apropriada para funcionar como a ponte entre o usuário e a mensagem que o mesmo deseja ou precisa ter acesso.

A vasta gama de desenhos tipográficos que é encontrada nas fontes digitais disponíveis para escolha passeia entre diferentes tendências estéticas. Ao observar os desenhos das fontes latinas é possível perceber dois caminhos projetuais distintos, que parecem dividir o grande grupo de tipografias em duas parcelas. A primeira é composta por tipos com desenhos mais expressivos que usualmente são referidos como tipos display. A segunda parcela é composta por tipos com desenhos mais parecidos entre si, que frequentemente são chamados de tipos de texto. Dentro do grupo das fontes displays são encontrados desenhos tipográficos com características formais mais evidentes e distintivas, uma vez que tais fontes são próprias para a composição de textos curtos em tamanhos grandes e não precisam necessariamente se ater aos preceitos da legibilidade. Já no grupo das fontes de texto, encontram-se desenhos

Anais do 8 CIDI e 8 CONGIC

Guilherme Santa Rosa; Cristina Portugal (orgs.)

Sociedade Brasileira de Design da Informação - SBDI

Natal | Brasil | 2017

ISBN 978-85-212-1305-5
Proceedings of the $8^{\text {th }} \mathrm{CIDI}$ and $8^{\text {th }}$ CONGIC

Guilherme Santa Rosa; Cristina Portugal (orgs.)

Sociedade Brasileira de Design da Informação - SBDI

Natal| Brazil | 2017

ISBN 978-85-212-1305-5 


\section{CIDI 2017

mais parecidos entre si, que tomam como referência os arquétipos formais pré-definidos dos caracteres: o modelo mental das letras (Noordzij, 2000). Portanto, é natural que o processo de escolha de tipografias de texto seja complexo, uma vez que fontes dessa natureza possuem desenhos mais discretos e são consequentemente mais difíceis de terem suas diferenças formais percebidas e interpretadas.

Porém, ainda que as fontes de texto sejam mais parecidas entre si, é inegável que todas elas possuem características formais distintas, que determinam as qualidades técnicas e conceituais que tal tipografia carregará. Antes de serem interpretadas enquanto formas que representam os caracteres alfabéticos, os desenhos tipográficos individualmente e fora do contexto de reprodução de uma informação textual, possuem valor enquanto elementos gráficos independentes, com características estilísticas que os identificam. A habilidade de interpretar tais desenhos pode conferir ao designer uma maior facilidade no momento de seleção dessas tipografias, uma vez que esses poderão realizar associações entre o desenho do tipo e o contexto de utilização do mesmo.

A presente pesquisa busca explorar o processo de escolha tipográfica dentro e fora do contexto da composição textual. O objetivo desse estudo é entender se existe diferença na interpretação do desenho tipográfico em duas situações de uso: a aplicação das fontes em manchas textuais e no projeto de de padrões ${ }^{1}$. Para montar o experimento, foram utilizadas como referências as pesquisas do laboratório Type Tasting (2016) e os padrões do projeto Hypenopaedia, idealizados pela designer de tipos Zuzana Licko (1997). A pesquisa foi realizada por trinta sujeitos, compostos por estudantes de design. $O$ arcabouço teórico tomado como suporte bibliográfico será exposto a seguir.

\section{Hypenopaedia: experimentos de padronagens tipográficas}

A crescente produção de novas fontes digitais e sua falta de proteção legal levou a designer de tipos Zuzana Licko (1997) a desenvolver um projeto constituído de uma série de padrões compostos por tipos (Figura 01), com o intuito de facilitar o entendimento do valor do desenho das fontes. A designer expõe que as letras, quando aplicadas no contexto de texturas ou ilustrações tipográficas, mostram de maneira mais explícita suas características estilísticas e conceituais. Quando os usuários enxergam dois desenhos de uma letra A, por exemplo, eles tendem a encarar ambos os desenhos de maneiras similares, uma vez que as duas são representações gráficas de uma letra. No contexto de padrões ou ilustrações, no entanto, as diferenças formais entre as fontes e suas possibilidades semânticas ficariam mais claras para o usuário. O projeto, batizado de Hypnopaedia, brinca com as formas e as contraformas das letras abdicando do fator de reconhecimento dos caracteres e priorizando a composição visual em detrimento das letras individuais. Para projetar a composição foram utilizadas sobreposições e rotações das letras, além de combinações de cores, originando 140 ilustrações diferentes.

Figura 1: Exemplos de módulos e padrões do projeto Hypenopaedia. Fonte: Zuzana Licko (1997).
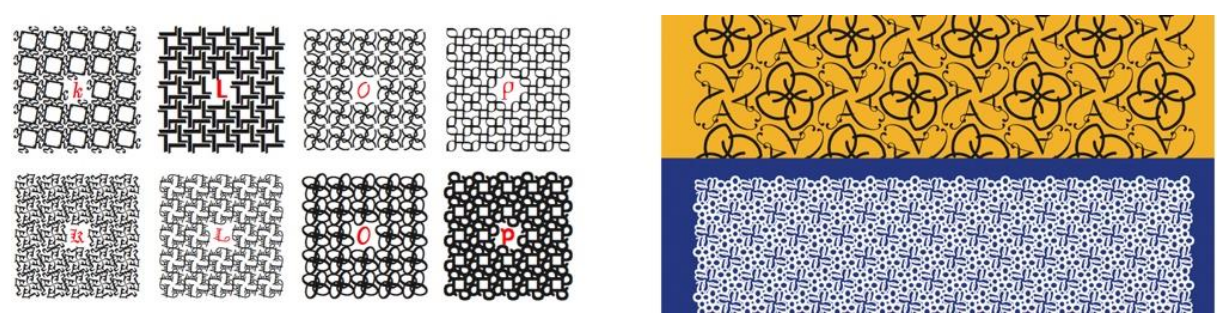

As fontes de texto tendem a possuir diferenças formais sutis entre si, devido ao extenso período de imersão do leitor no texto no momento da leitura, fato que exige que a fonte possua desenhos mais simples para que as palavras sejam decifradas com o mínimo de esforço e máximo de eficácia. Apesar de discretas, as minusciosidades do desenho tipográfico das fontes de texto revelam detalhes relevantes para a sua utilização, uma vez que cada tipografia se

\footnotetext{
${ }^{1}$ Esse documento utilizado o termo padronagem como sinônimo para padrões, ao referenciar repetições ordenadas de um módulo.
} 
adequará melhor a algum contexto em relação a outro. Apesar de não ser algo fácil ou trivial, a capacidade de diferenciação e interpretação dessas formas é de grande valia para o processo de seleção de tipos.

A presente pesquisa utiliza a premissa de Licko (ibid) de que os desenhos tipográficos mostram suas características mais explicitamente no contexto de padronagens, procurando fazer um paralelo de tais composições com o processo de escolha tipográfica. A escolha tipográfica para um determinado problema será comparada nas duas situações de uso, os padrões e a mancha textual, com o intuito de explorar se houve dissonância na escolha da fonte nessas duas realidades, e se as texturas tipográficas são capazes de facilitar o processo de escolha.

\section{Typetasting: um laboratório de experiências tipográficas}

Ainda que a legibilidade seja uma qualidade fundamental para fontes de texto, não podemos ignorar que as características formais do desenho tipográfico também carregam consigo outras qualidades que podem ser observadas no tipo: aquelas mais relacionadas às questões conceituais. Tais possibilidades semânticas também podem funcionar como guias e facilitar o processo de seleção de fontes para o projeto de um determinado artefato gráfico. É importante observar que as qualidades subjetivas carregadas pelas fontes de texto não se encerram em suas formas e podem ser alteradas de acordo com diversos fatores tais como o seu tratamento na composição de um artefato gráfico, ou até mesmo com a bagagem cultural do usuário ou o conteúdo da mensagem textual. No entanto, o entendimento preliminar das possibilidades semânticas do desenho das letras pode ser encarado como o primeiro passo para uma compreensão mais aprofundada sobre o assunto.

Ao longo da pesquisa bibliográfica foram encontrados alguns estudos que abordam, sob diferentes óticas, a relação entre tipografia e significado. Uma das mais conhecidas pesquisas sobre a temática foi realizada por Brumberger (2003). O estudo revelou que o leitor é capaz de perceber a apropriação de determinadas tipografias a determinados textos, e que a escolha tipográfica pode afetar a percepção do leitor das personalidades dos escritos. Também destacam-se as pesquisas de Mackiewicz \& Moeller (2004), Li \& Suen (2010) e Dyson \& Stott (2012), que abordam de maneira similar o assunto. Tais pesquisas fornecem várias informações acerca da relação entre a análise formal do tipo e suas possíveis características conceituais.

Na pesquisa realizada por Falcão (2014), foram realizados testes com usuários a fim de testar a atribuição de 6 grupos conceituais (Sofisticação, Peso, Expressividade, Movimento, Época e Espírito) a 12 fontes de texto (Baskerville, Bodoni, Garamond, Palatino, Rockwell, Times New Roman, Calibri, Futura Std, Gill Sans, Helvetica, Tahoma e Trebuchet MS). Os grupos conceituais foram elaborados a partir da proposta de análise formal de Falcão \& Aragão (2012) e as fontes foram escolhidas por sua disponibilidade dos sistemas operacionais da Apple e da Microsoft. Os resultados do estudo revelam que os usuários, apesar de não conseguirem necessariamente diferenciar fontes de texto apresentadas comparativamente em manchas textuais, conseguem atribuir conceitos subjetivos quando apresentados às manchas textuais individualmente.

Hyndman (2016), pesquisadora responsável pelo laboratório Type Tasting, expõe uma série de pesquisas realizadas com o intuito de relacionar desenhos tipográficos a tons de voz, emoções, personalidades, entre outros (Figura 02). As pesquisas utilizam em sua maioria fontes de texto e sua idealizadora ressalta que os resultados são um ponto de partida para uma discussão mais aprofundada sobre o assunto. Os estudos de Hyndman (ibid) se destacam devido a difusão da tipografia como um artefato multi-sensorial e da sua importância na formação do repertório visual não apenas dos designers, mas também dos usuários nãoespecialistas. 


\section{CIDI 2017

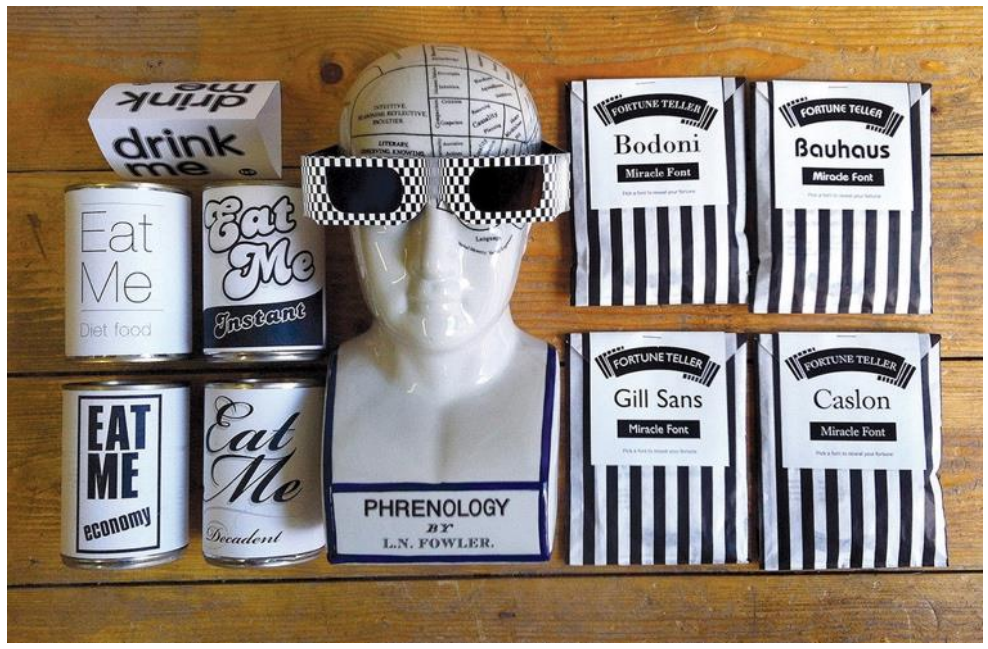

As experiências do TypeTasting incluem os participantes em dinâmicas participativas e sensoriais, que procuram interagir com os cinco sentidos humanos e criar experiências que os mesmos possam posteriormente relacionar com a escolha do tipo. No tocante ao paladar, foram realizados experimentos explorando a relação da tipografia e sua relação com os quatro sabores primários: o amargo, o salgado, o doce e o azedo. Neles, são investigadas as relações entre os gostos, as marcas gráficas abstratas e as formas tipográficas, bem como a relação entre a tipografia e a embalagem de comidas. Por serem mais acessíveis para os participantes devido a sua interatividade e dinamicidade, as pesquisas do Type Tasting foram utilizadas como referência para a estruturação do presente experimento, conforme será explicado a seguir.

\section{0 experimento}

Para explorar o processo de escolha tipográfica, foi idealizado um experimento onde os participantes pudessem fazer uma relação entre fontes de texto em duas situações de uso (padrões e mancha textual) e os sabores primários. Foram escolhidos como sujeitos um grupo de estudantes de design devido a sua dualidade no tocante a familiaridade com a tipografia. Tais especialistas possuem algum conhecimento sobre os tipos, porém, por não acumularem experiência profissional, ainda possuem grandes dificuldades para selecionar fontes de texto. Para a formatação do experimento, foi elaborado um sistema de montagem de embalagens para os seguintes produtos:

- Leite com chocolate, representando o sabor doce;

- Suco de limão, representando o sabor azedo;

- Sopa de queijo, representando o sabor salgado;

- Café, representando o sabor amargo;

- Água, representando um sabor neutro.

O sistema foi constituído por cinco garrafas brancas, cada uma contendo um dos líquidos descritos acima. Na frente de cada garrafa constavam cinco rótulos com o nome e a descrição do líquido, projetados com cada uma das fontes selecionadas para o estudo. Logo a frente do conjunto de garrafas e rótulos, foram dispostos os cinco padrões também projetados com cada uma das fontes selecionadas (Figura 03). O processo de seleção das fontes escolhidas para compor esse estudo, o projeto dos padrões e dos rótulos, e seu protocolo de realização serão descritos a seguir. 


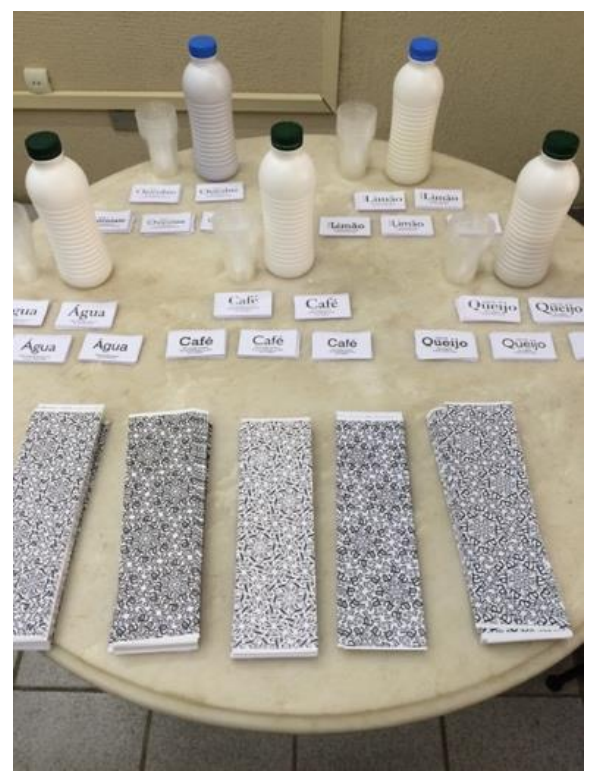

\section{A escolha das fontes}

A formatação da pesquisa teve início com a escolha das fontes de texto que fariam parte do estudo. Foi determinado que as tipografias selecionadas deveriam estar disponíveis nos sistemas operacionais Mac OS e Windows, ou seja, que fossem constituintes do repertório visual dos participantes, e que fossem fontes próprias para a composição de textos longos. Após observar os desenhos tipográficos disponíveis, foram selecionadas as fontes Helvetica, Gill Sans, Rockwell, Garamond e Didot (Figura 04) em suas versões regulares. Os materiais bibliográficos consultados apontam que tais desenhos tipográficos (ou fontes pertencentes às mesmas categorias de classificação tipográfica de tais tipografias) costumam ser utilizados para pesquisa sobre semântica, pois apresentam em seus arquétipos formais mudanças de desenho significativas.

Figura 04: As fontes de texto selecionadas para a pesquisa. Fonte: Elaborada pelos autores.

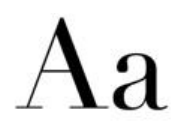

Didot

\section{$\mathrm{Aa}$}

Gill Sans

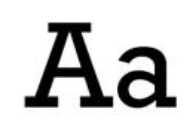

Rockwell

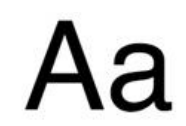

Helvetica

\section{Aa}

Garamond

\section{O projeto dos padrões}

Foram realizados alguns estudos (Figura 05) de como os padrões poderiam ser produzidos de maneira a mascarar a percepção do usuário do valor textual dos caracteres tipográficos. $O$ intuito final seria mascarar as letras, para que o observador, à primeira vista, não enxergasse as letras dispostas numa superfície, mas sim uma textura ilustrativa. Ao contrário dos padrões produzidos por Licko (1997), as padronagens desenvolvidas para essa pesquisa não utilizaram nenhum elemento extrínseco ao desenho do tipo, tampouco sobreposições dos caracteres. A letra escolhida para a composição dos padrões foi o "a", por ser um dos caracteres mais passíveis de mudanças estruturais e, portanto, capaz de transmitir uma maior carga de diferenças formais e informações conceituais (Falcão \& Coutinho, 2015). 
Figura 05: Geração de alternativas das padronagens tipográficas. Fonte: Elaborada pelos autores.

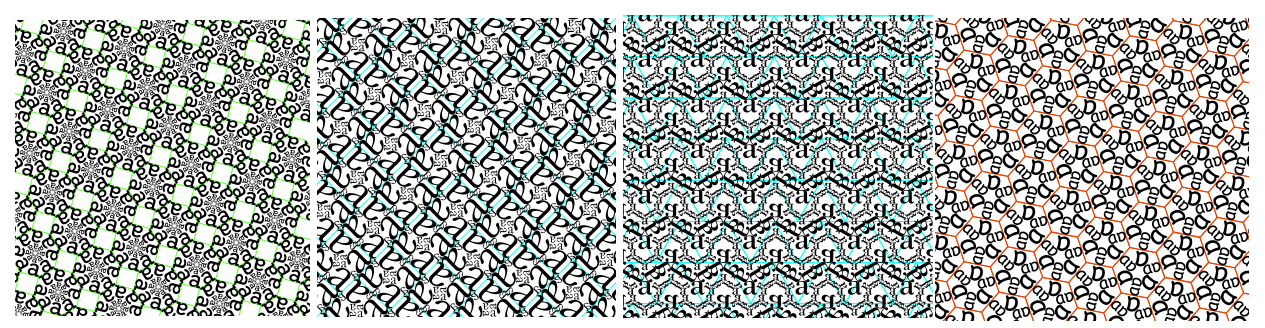

Para dar início ao projeto das padronagens que seriam utilizadas na pesquisa, foi necessário igualar o tamanho ótico das fontes, através da equalização da altura-x dos caracteres. Uma das premissas básicas para a criação de padrões é o entendimento dos módulos e dos sistemas de repetição (Rüthschilling, 2008). Na presente pesquisa foi escolhido como módulo uma forma hexagonal (Figura 06). Seu projeto de preenchimento foi escalado para as cinco fontes selecionadas, originando por fim os cinco padrões (Figura 07).

Figura 06: Exemplo do projeto do módulo (nesse exemplo utiliza-se a fonte Didot) utilizado para a composição dos padrões. Fonte: Elaborada pelos autores.

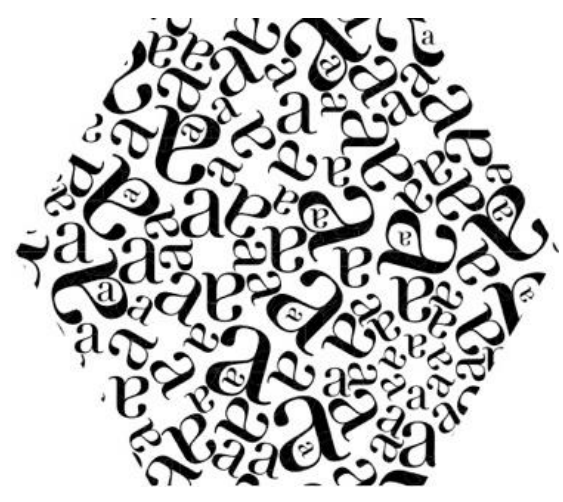

Figura 07: Padrões confeccionados com as fontes Didot, Gill Sans, Helvetica, Garamond e Rockwell. Fonte: Elaborada pelos autores.
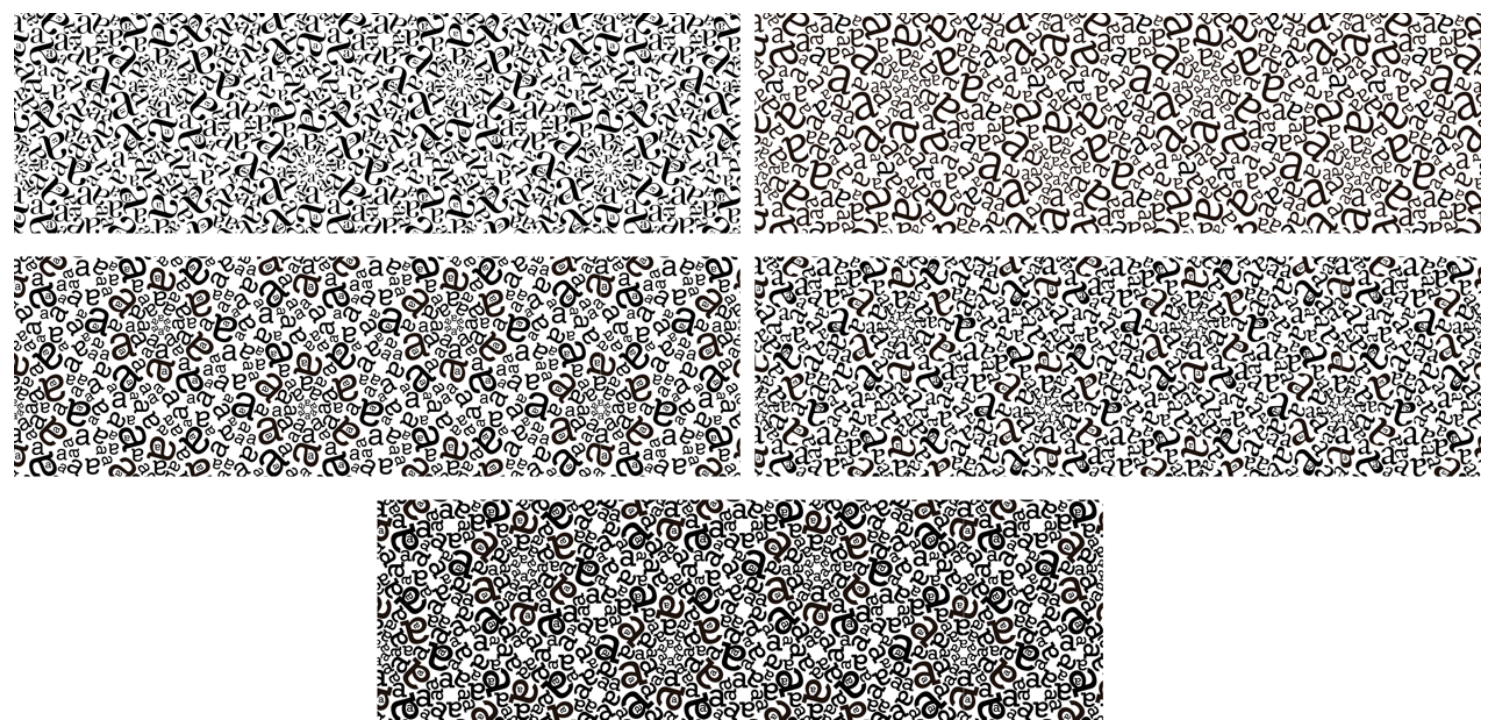

\section{O projeto dos rótulos}

Os rótulos que funcionariam como a composição textual a ser comparada com as padronagens foram projetados para ressaltar as fontes utilizadas. As informações textuais referentes ao nome e às características do líquido em questão foram hierarquizadas de acordo com a sua 


\section{CIDI 2017

importância. Vale salientar que a única variação entre os rótulos foi a fonte utilizada: não existiram variações de cor, diagramação, dimensão ou ilustração (Figura 08).

Figura 08: Exemplos dos rótulos confeccionados para o suco de limão, com as fontes Garamond, Rockwell, Helvetica Didot e Gill Sans. Fonte: Elaborada pelos autores.
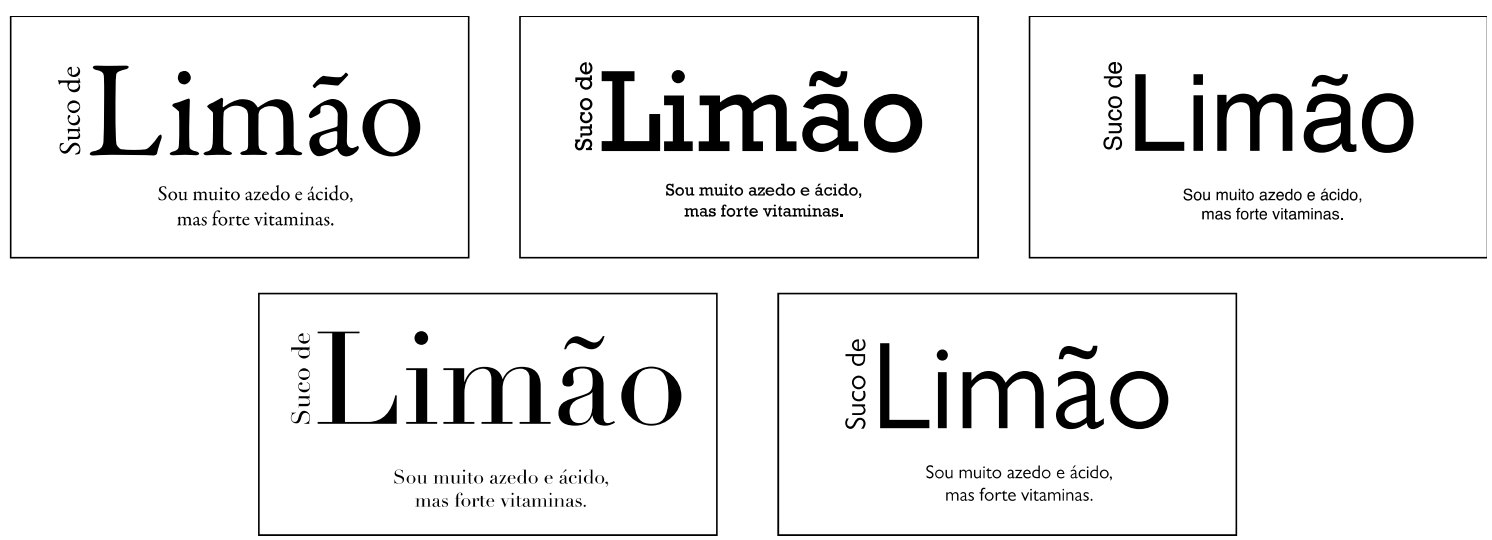

\section{O protocolo do experimento}

O experimento foi realizado individualmente com trinta estudantes de design. No primeiro momento foi pedido que os usuários observassem as bebidas através da leitura das informações dos rótulos e que as experimentassem. Posteriormente os usuários foram orientados a escolherem um papel para embrulhar cada uma das garrafas, aquele que eles julgassem que combinaria mais com o sabor do líquido em questão. Após embrulhar as garrafas, os usuários escolheram um rótulo para cada um dos líquidos: o rótulo que eles julgassem mais adequado (Figura 09). Após montarem as embalagens para as bebidas, os usuários foram questionados sobre qual dos dois artefatos gráficos foi o mais fácil de escolher, o padrão ou o rótulo.

Figura 09: Participantes realizando o experimento. Fonte: Elaborada pelos autores.

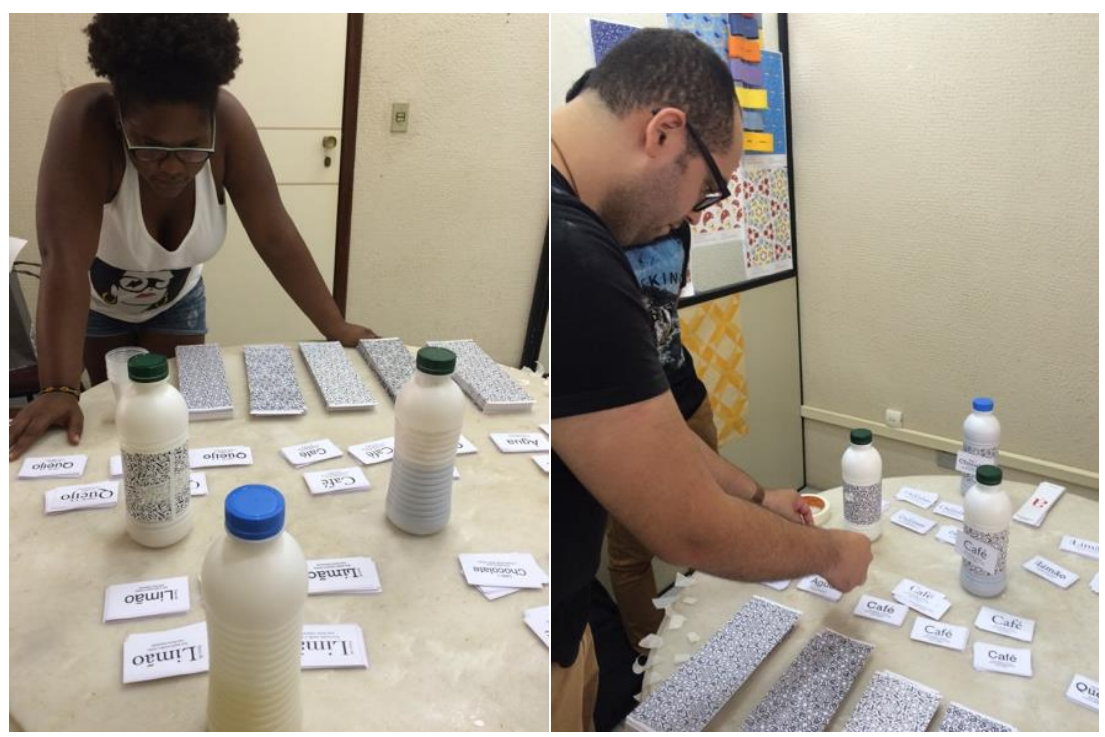

\section{Resultados da pesquisa}

Os conjuntos das embalagens montadas pelos participantes foram guardados separadamente, organizados pelos sabores primários abordados na pesquisa. Após o término do experimento foram contabilizadas as recorrências das fontes escolhidas através da contagem de todos os rótulos e padrões escolhidos. Essa pesquisa não analisou as interações das fontes selecionadas em cada situação de uso (o par rótulo/padrão), foi buscada apenas a análise quantitativa da recorrência das tipografias em cada um dos artefatos apresentados. A tabela a 
seguir (Tabela 01) apresenta as fontes mais escolhidas para cada uma das situações de uso, em cada um dos sabores apresentados:

Tabela 1: Tabela descritiva dos resultados do experimento. Fonte: Elaborada pelos autores.

\begin{tabular}{l|l|l|l} 
Bebida & Sabor & $\begin{array}{l}\text { Fonte mais } \\
\text { escolhida } \\
\text { para o } \\
\text { padrão } \\
\text { (recorrência) }\end{array}$ & $\begin{array}{l}\text { Fonte mais } \\
\text { escolhida } \\
\text { para o rótulo } \\
\text { (recorrência) }\end{array}$ \\
\hline $\begin{array}{l}\text { Leite com } \\
\text { chocolate }\end{array}$ & Doce & Rockwell (9) & Rockwell (11) \\
\hline Suco de limão & Azedo & Didot (10) & Didot (9) \\
\hline Sopa de queijo & Salgado & Gill Sans (10) & $\begin{array}{l}\text { Garamond } \\
(10)\end{array}$ \\
\hline Café & Amargo & Rockwell (17) & Didot (10) \\
\hline Água & Neutro & Didot (12) & Helvetica (11) \\
\hline
\end{tabular}

É importante destacar que quase $100 \%$ dos usuários afirmaram que foi mais difícil escolher os padrões do que os rótulos. Tal informação descarta a hipótese de que os padrões tipográficos possam facilitar o processo de escolha de fontes de texto. Muitas vezes os padrões confundiram os participantes e esses acabaram por diferenciar as opções através da cor da textura, o que nos leva a crer que atributos formais como o peso das fontes (a relação entre a forma e a contraforma da letra) foi um fator determinante para a diferenciação. O aspecto tonal da fonte também pareceu ter se mostrado relevante no momento da associação das padronagens com os líquidos apresentados.

Em bebidas claras, tais como a água, o suco de limão e a sopa de queijo, as fontes mais escolhidas foram a Didot e a Gill Sans, que originaram os dois padrões com os aspectos tonais mais leves do conjunto. Na escolha da fonte dos rótulos de tais bebidas, houve uma dissonância: a Didot foi escolhida mais uma vez para Suco de Limão, no seu rótulo. Para o rótulo da Água foi selecionada a Helvetica e para a Sopa de Queijo, observa-se que a fonte escolhida para o rótulo descritivo foi a Garamond. No projeto dos rótulos, as características formais das fontes ficaram mais evidentes, fato que pode ter influenciado a escolha dessas tipografias específicas. Fontes como a Helvetica são frequentemente associadas em estudos sobre semântica da tipografia (FALCÃO, 2014) como comuns quanto ao seu espírito, ou seja, uma fonte sem personalidade. Nesse experimento, a Helvetica foi selecionada para o rótulo do líquido de sabor neutro, corroborando os estudos anteriores. Já a Didot, ou outras fontes pertencentes a categoria didônicas ${ }^{2}$, são associadas com elegância, delicadeza e leveza, e nessa pesquisa foi associada ao líquido azedo. A Garamond, associada previamente à elegância e a tradicionalidade (FALCÃO, ibid), foi associada nesse estudo ao sabor salgado.

Ainda no âmbito do aspecto tonal, a bebida Leite com Chocolate, representante do sabor doce, foi mais uma situação de recorrência da fonte utilizada no padrão e no rótulo, no caso, a Rockwell. As formas arredondadas e o peso acentuado da tipografia podem ser encarados como fatores determinantes para a escolha, fato comentado por diversos participantes ao longo do experimento. Muitos também destacaram a relação com o seu repertório visual de rótulos e de anúncios publicitários de leites achocolatados e produtos afins. O café, a outra bebida escura do conjunto, que na ocasião representou o sabor amargo, também foi relacionado ao padrão da fonte Rockwell, reforçando o fator da cor da padronagem. No entanto, seu rótulo foi relacionado a fonte Didot, uma possível referenciação à elegância evocada em algumas situações relacionadas ao hábito de ingerir o café.

2 Utilizamos como referência neste artigo o Sistema de Classificação Tipográfica BS 2961, proposto pela British Standards Institution em 1967 (SILVA \& FARIAS, 2004). 


\section{Considerações Finais}

A escolha de fontes de texto faz parte do processo de trabalho qualquer profissional que atue na área do design gráfico. Ao se tratar de mensagens majoritariamente textuais, faz-se necessário o entendimento das formas tipográficas, de modo a efetuar de maneira coerente a escolha da fonte que será utilizada para a configuração da informação verbal. Assim, a tipografia atuará como aliada do Design da Informação, não apenas como mera representação gráfica, mas também como um participante ativo capaz de auxiliar a relação entre a mensagem e o usuário.

O presente estudo buscou explorar a assimilação das diferenças formais entre as fontes de texto quando essas são utilizadas na criação de padronagens em comparação a tradicional composição textual. Utilizou-se como base para a estruturação da pesquisa a premissa da designer de tipos Zuzana Licko (1997) de que as letras, quando aplicadas no contexto de texturas mostram de maneira mais explícita suas características estilísticas e conceituais. Também foram utilizadas como referência as pesquisas referentes a capacidade multi-sensorial da tipografia do laboratório Type Tasting (2016), para estruturar um experimento conduzido com trinta usuários estudantes de design. O experimento foi realizado na forma de montagem de embalagens para bebidas, compostas por um padrão e um rótulo descritivo.

O estudo revelou que os usuários possuem mais dificuldades para diferenciar as fontes de texto quando essas atuam como matéria prima para a composição de padrões da maneira projetada para essa pesquisa. De uma maneira geral, os participantes revelaram que a escolha do rótulo (a composição textual) foi mais fácil do que a escolha das padronagens. Pode-se levantar como possibilidade para estudos futuros, projetos de diferentes padrões com outros formatos de módulos ou até mesmo utilizando outros caracteres das fontes em questão.

É interessante perceber que no experimento estruturado, as fontes de texto foram utilizadas para a composição de textos curtos, onde uma palavra aparecia em um tamanho maior, e as demais em tamanhos adequados para a composição de textos longos. No entanto, a composição textual em menor escala foi curta e não necessariamente revelou a característica final do que seria uma mancha textual de um texto corrido composto com tais fontes. Portanto, destaca-se também como possibilidade para uma futura pesquisa, a estruturação de artefatos com manchas textuais mais extensas.

A relação entre a tipografia, os sabores e as marcas gráficas abstratas se revelaram como bom ambiente de pesquisa para entender mais a fundo as possibilidades conceituais das fontes de texto. Estudos envolvendo o relacionamento dos três elementos são uma boa oportunidade de aumentar o engajamento dos usuários nas pesquisas, uma vez que a interação presencial com os artefatos faz com que a pesquisa se torne mais dinâmica.

No tocante as possibilidades semânticas das fontes escolhidas para o estudo (Garamond, Didot, Rockwell, Helvetica e Gill Sans), foi observada uma coerência entre as informações recolhidas aqui, e as reveladas por estudos prévios. $O$ fato aponta que as pesquisas sobre a semântica tipográfica são imprescindíveis para um total entendimento das possibilidades de uso das fontes de texto. Ainda assim é necessário um estudo mais aprofundado sobre o assunto, pois as possibilidades de pesquisa ainda não se encerraram. Pesquisas que envolvam não apenas os fatores intrínsecos à tipografia, mas também os fatores extrínsecos podem ser de grande valia para o entendimento das possibilidades semânticas da tipografia, uma vez que no projeto de artefatos gráficos geralmente o elemento verbal interage com outros elementos da linguagem gráfica.

Por fim, aponta-se como necessário a realização de outros estudos sobre o processo de escolha tipográfica de fontes de texto. Foi possível perceber, ao longo do experimento relatado nesse artigo, que a seleção de fontes ainda é algo de difícil realização para o grupo participante desse estudo: os estudantes de design. Ainda que sejam expostos a teorias que devem ser aplicadas no momento da seleção do tipo, ainda se percebe um abismo entre o conhecimento adquirido na Academia e a aplicação do mesmo no processo projetual de artefatos gráficos.

\section{Agradecimento}

Gostaríamos de agradecer à AESO - Faculdades Integradas Barros Melo, por fomentar essa pesquisa e disponibilizar o espaço físico para a realização da mesma. 


\section{Referências}

Artigos em revistas acadêmicas/capitulos de livros

BRUMBERGER, Eva. 2003. The Rhetoric of Typography - The awareness and Impact of Typeface Appropriatness. Technical Communication; May 2003; 50, 2; Humanities Module.

DYSON, Mary; STOTT, Caroline. 2012. Characterizing typographic expertise: Do we process typefaces Like Faces? Visual Cognition Volume 20, Issue 9.

ESTEVES, Ricardo. 2010 O design brasileiro de tipos digitais - a configuração de um campo profissional. São Paulo: Blucher.

FALCÃO, Luiza; 2014. As possibilidades semânticas das fontes de texto: Um estudo a partir da prática projetual do designer de tipos. 146 f. Dissertação (Mestrado em Design) Universidade Federal de Pernambuco, Recife (PE).

FALCÃO, Luiza; ARAGÃO, Isabella. 2012. Um estudo entre forma e conteúdo em livros de literatura: uma proposta de análise. Anais do $10^{\circ}$ Congresso Brasileiro de Pesquisa e Desenvolvimento em Design, São Luís (MA).

FALCÃO, Luiza; COUTINHO, Solange. 2015. A relação dos usuários especialistas e nãoespecialistas com as fontes de texto: distinção e atribuição de conceitos subjetivos. Anais do $7^{\circ} \mathrm{CIDI}$ e $7^{\circ} \mathrm{CONGIC}$, Brasília (DF).

FARIAS, Priscila \& SILVA, Fabio Luiz Carneiro Mourilhe. 2004. Classificações tipográficas: sistemas de classificação cruzada. FAAP São Paulo: Anais do P\&D Design 2004 - $6^{\circ}$ Congresso Brasileiro de Pesquisa e Desenvolvimento em Design.

FRUTIGER, Adrian. 2007. Sinais e Símbolos. São Paulo: Editora Martins Fontes.

GILL, Eric. 1931. An Essay on Typography. London: Sheed \& Ward Gill, E

HYNDMAN, Sarah. 2016. Why fonts matter. Londres: Virgin Books.

Li, Ying; SUEN, Ching. 2010. Typeface Personality Traits and Their Design Characteristics. DAS '10 Proceedings of the 9th IAPR International Workshop on Document Analysis Systems.

LUPTON, Ellen. 2006. Pensar com tipos. São Paulo: Cosac Naify.

MACKIEWICZ, Jo; MOELLER, Rachel. 2004. Why people consider typefaces to have diferente personalities. Professional Communication Conference, 2004. IPCC.

NOORDZIJ, Gerrit. 2000. Letterletter. Vancouver: Hartley \& Marks.

SMEIJERS, Fred. 2011. Counterpunch: Making type in the sixteenth century designing typefaces now. London: Hyphen Press.

STOCKL, Hartmut. 2005. Typography: body and dress of a text - a signing mode between language and image. Visual Comunication, v. 4, n.2.

TRACY, Walter. 1986. Letters of Credit. London: Gordon Fraser.

Textos publicados na internet

HAAG, Fabio. 2014. Basta uma letra para contar uma história. In: http://www.bdxpert.com/2010/12/06/basta-uma-letra-para-contar-uma-historia/, 01/06/2014.

MYFONTS. 2016. In: <http://www.myfonts.com/newsletters/cc/201211.html>, 10/06/2017.

\section{Sobre o(a/s) autor(a/es)}

Luiza Falcão Soares Cunha; doutoranda em Design pela UFPE, professora assistente do curso de Design da UFRN, Brazil <luizafsc@gmail.com>

Luis Felipe Cavalcanti; Graduando, AESO - Faculdades Integradas Barros Melo, Brazil

$<$ felippecavalcantiart@gmail.com> 